\title{
Artificial Intelligence Possibilities in Vehicle Industry
}

\author{
J. MENYHART \\ University of Debrecen, Faculty of Engineering, Department of Mechanical Engineering, \\ jozsef.menyhart@eng.unideb.hu
}

Abstract: There have been several attempts during the last decades to extend the ranges of application of artificial intelligence. The aim of the development for AI is to replace human intelligence and experience. The ultimate aim for machines and vehicles is to run much more efficiently and with higher reliability than ever before. The Artificial Techniques (AI) used a wide range of expert systems to optimize problems. Hybrid intelligent management systems have become increasingly influential in artificial intelligence during the last decades. As a result, maintenance and fleet management systems have undergone significant development. By choosing adequate maintenance or operating strategy and taking user behaviour into consideration, these systems can not only increase the reliability and efficiency of vehicles but can also result in financial savings. The paper tries to discusses the applications of AI techniques in predictive maintenance and vehicle industry.

Keywords: Industry 4.0, Artificial Intelligence, M2M, M2H, Vehicle Industry

\section{Introduction}

Enterprises are able to gain much more data than ever before. These data allow them to measure and analyse their activities. Consequently, enterprises are able to eliminate waste from their processes, produce their products and services in higher quality, but it may be an even more important point that they can reduce cost. It is enough to think of the development of vehicles or the disruptive changes in the vehicle industry. [3] [5]

The concept of Industry 4.0 and other related definitions have been published including machine-tomachine (M2M), machine-to-humans (M2H), cloud computing, etc. Artificial intelligence has existence in each field including operation, maintenance, human resource, autonomous vehicles, etc. The predictive maintenance is the most important maintenance strategy in the modern autonomous vehicles. Just enough to think about self-check processes or OBD systems. [3] [5]

\section{Artificial Intelligence Software}

There was strong need for the development of IT tools and software in order to do so. Artificial intelligence software requires the followings [3]:

- "collects information from sensors,"

- "monitors anomalies and patterns," 
International Journal of Engineering and Management Sciences (IJEMS) Vol. 4. (2019). No. 4

- "uses that information to request for human intervention."

In the practice we know two ways AI monitors the information coming out of assets [3]:

- "Anomaly: The system reads data generated from the equipment and picks up any variations from normal running conditions."

- "Failure: This focuses on data patterns to detect a potential failure based on similarities with predefined failure modes."

Both of these can generate problems what the system can analyse and check. Thanks for the Big Data systems and other Industry 4.0 tools the users and maintenance team know that there's a need to investigate the situation. Very popular to combine the two methods and check the user habits next to them, like environmental properties, company culture, human habits etc. The predictive maintenance strategy can give input data to the condition based maintenance. These strategies can walk hand in hand in vehicles and in industrial facilities. [1] [3] [5]

Predictive maintenance is amongst the most crucial maintenance strategies that is more efficient than ever due to modern IT tools. It requires the followings [1] [3]:

- "Data acquisition, storage - Cloud or edge systems,"

- "Data transformation - Conversion of raw data for machine learning models,"

- "Condition monitoring - Alerts based on asset operating limits,"

- "Asset health evaluation - Diagnostic records based on trend analysis if asset health declines,"

- "Prognostics - Failure predictions through machine learning models, estimate remaining life,"

- "Decision support system - Best action recommendations,"

- "Human interface layer - Information accessible in easy-to-understand format."

Due to predictive maintenance, it is possible to spot several defects that men do not or cannot detect. A number of enterprises applies this strategy to increase efficiency. Automotive industry is one of the most significant field of predictive maintenance. This maintenance strategy is particularly important in self-monitoring and condition monitoring processes of vehicles. It is a critical issue for batterypowered vehicles that are gaining ground. The aim of engineers and enterprises is to maximize the range of electric vehicles by artificial intelligence and real-time data collection. [1] [3] [5]

\subsection{Soft Computing Methods}

The soft computing method of predictive maintenance includes the followings- Knowledge Based Systems (KBS). [1] [10]

- Fuzzy Logic,

- Case Based Reasoning,

- Genetic Algorithms,

- Neural Networks, 
- Data Mining,

- Hybrid Systems.

It is important to emphasize that artificial intelligence exists in other fields, as well. These include the followings [1]:

- Housekeeping,

- Inventory Management,

- Robots,

- Fleet management,

- Virtual Reality.

\section{Vehicle Industry - Vehicles}

Regarding research and development, automotive industry, due to the advent of electric and autonomous cars, is undergoing significant changes these days. Autonomous driving is not a development, but a revolution itself. The development of autonomous cars is timely in terms of road traffic safety. An autonomous car is able to drive on the road without human intervention, detects and evaluates the environment, guides and navigates itself with digital technologies. With the spread of autonomous cars, the role of individual property recedes into the background and the use of community cars and car sharing are gaining ground. Several enterprises, including Google, Tesla Motors, Nissan, Toyota, Volkswagen / Audi, Mercedes-Benz, Delphi Automotive and Bosch, are independently carrying out researches and developing autonomous cars. [2] [4] [6]

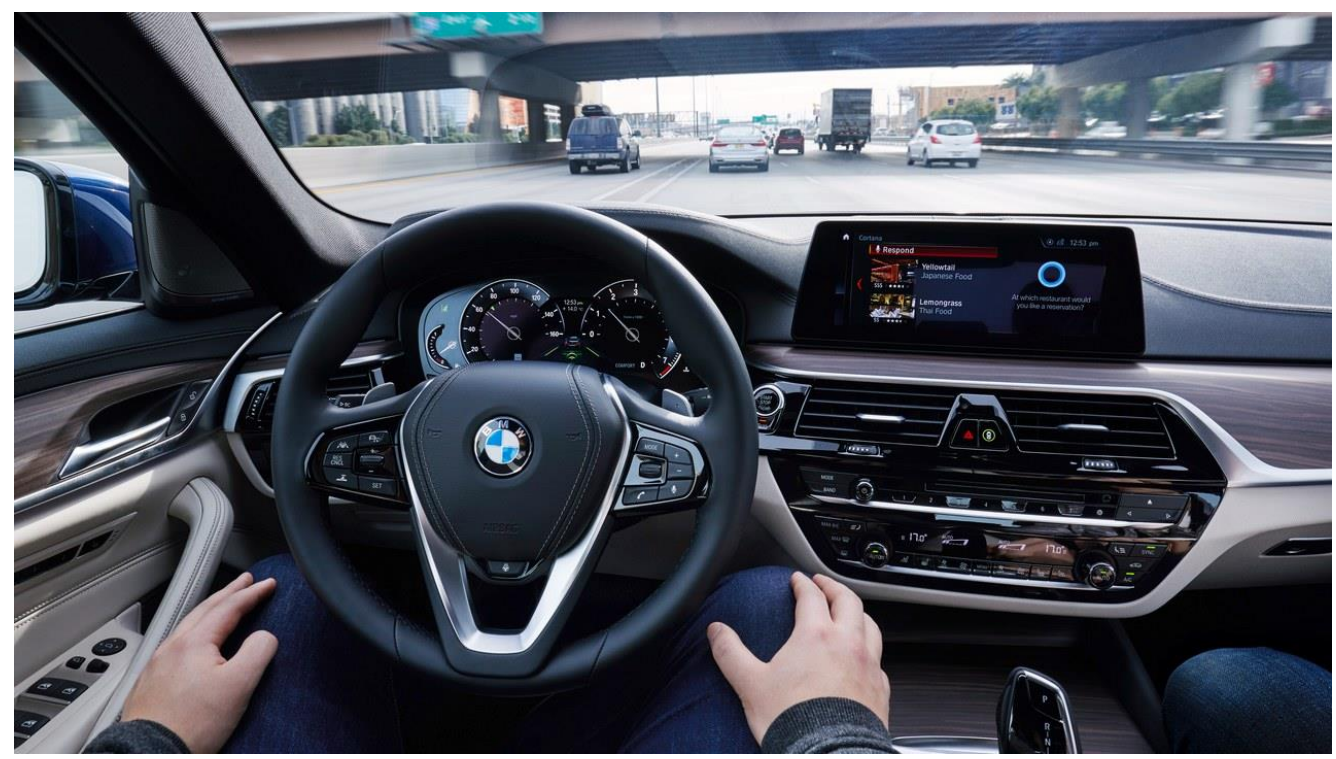

Figure 1. BMW Autonomous technology In the 7 series model (2017) [6] 


\subsection{Levels of Automation}

In 2014, SAE (Society of Automotive Engineers) International defined a standard for autonomous robot cars in terms of automation. Consequently, we will review 6 levels of the automatic driving system standard [4] [7]:

- Level 0, No Automation: the traditional car is completely man-controlled, there is no automation, and the driving environment is man-monitored.

- Level 1, hands on, Drive Assistance: the car is completely man-controlled, driving assistance when steering or braking / accelerating, and the driving environment is man-monitored.

- Level 2, hands off, Partial Automation: The car is completely man-controlled, with partial automation, the driver assistance system may take over steering and braking / acceleration operations at the same time and the driving environment is man-monitored. The automated system monitors the traffic environment.

- Level 3, eyes off, Conditional Automation: Conditional automation, the car is completely mancontrolled, the driver assistance system may take over the steering and braking / acceleration operations at the same time and the driving environment is monitored by automatic system.

- Level 4, mind off, High Automation: high level of automation, automatic driving system controls all the dynamic driving operations, the driving environment is monitored by automatic system.

- Level 5, steering wheel optional, Full Automation: complete automation, the automatic driver system continuously controls all dynamic driving operations, the driving environment is monitored by automatic system, and the car may run without man.
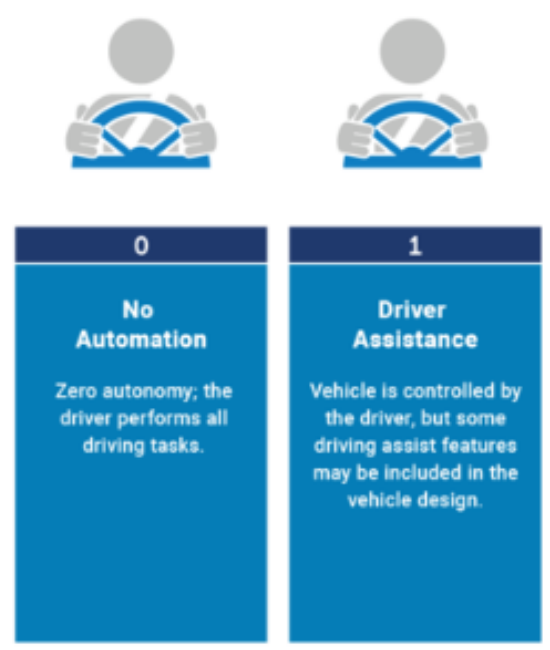
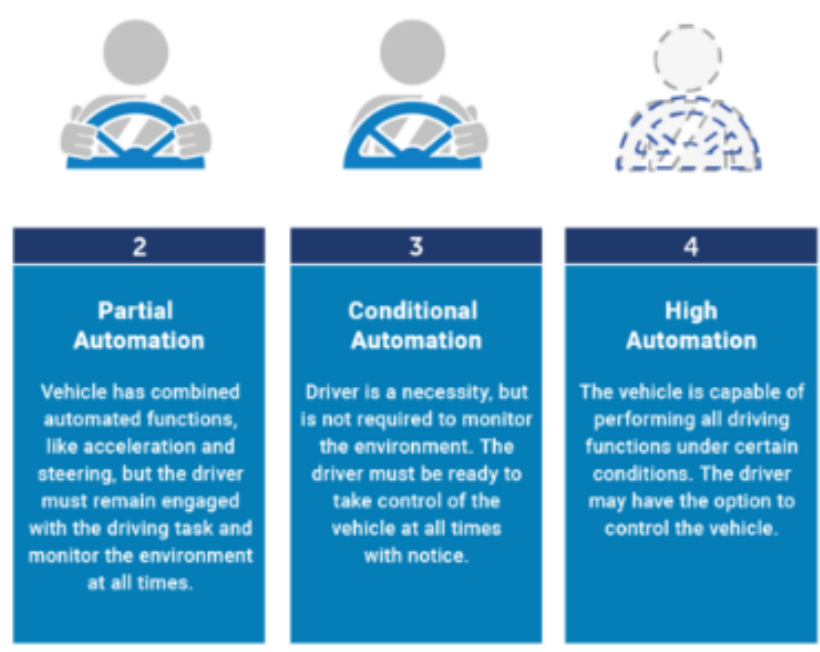
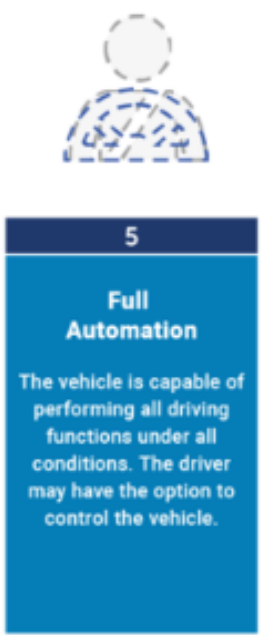

Figure 2. The levels of Automation [7]

\section{Vehicle Industry - Manufacturing}

Artificial intelligence not only brings new capabilities to the vehicle and its associated auxiliaries, it also has a profound effect on vehicle manufacturing processes. Robots in vehicle production lines are not new. They have been available since the 1960s to support various workflows. What is new is that 
robots are able to work with men. In 2018, KIA Motors started to develop a special equipment with Hyundai called Vest Exoskeleton (H-VEX). The H-VEX and Hyundai Chairless Exoskeleton (H-CEX) are great help in protecting operator's joints. [4] [8]

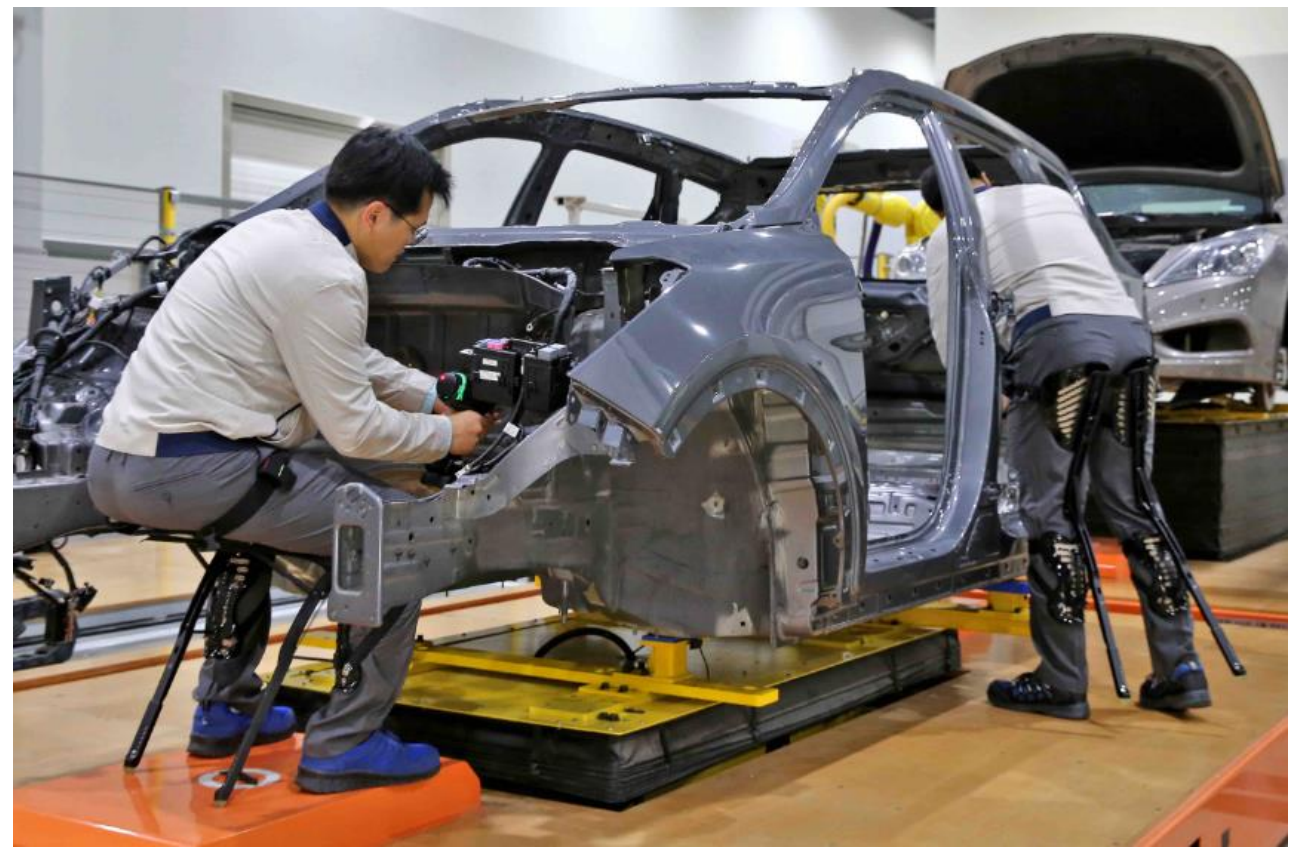

Figure 3. H-EX exoskeleton in manufacturing [8]

The collaborative robots use AI to sense what human workers are doing, check their activity and health condition. These kinds of robots adjust their motions to avoid injuring humans or other vehicles and machines. Automated Guided Vehicles (AGVs) are being used to move materials around industrial facilities without any human control. AI enables these autonomous delivery vehicles to identify objects in their paths, and to adjust their route accordingly. [8] [9]

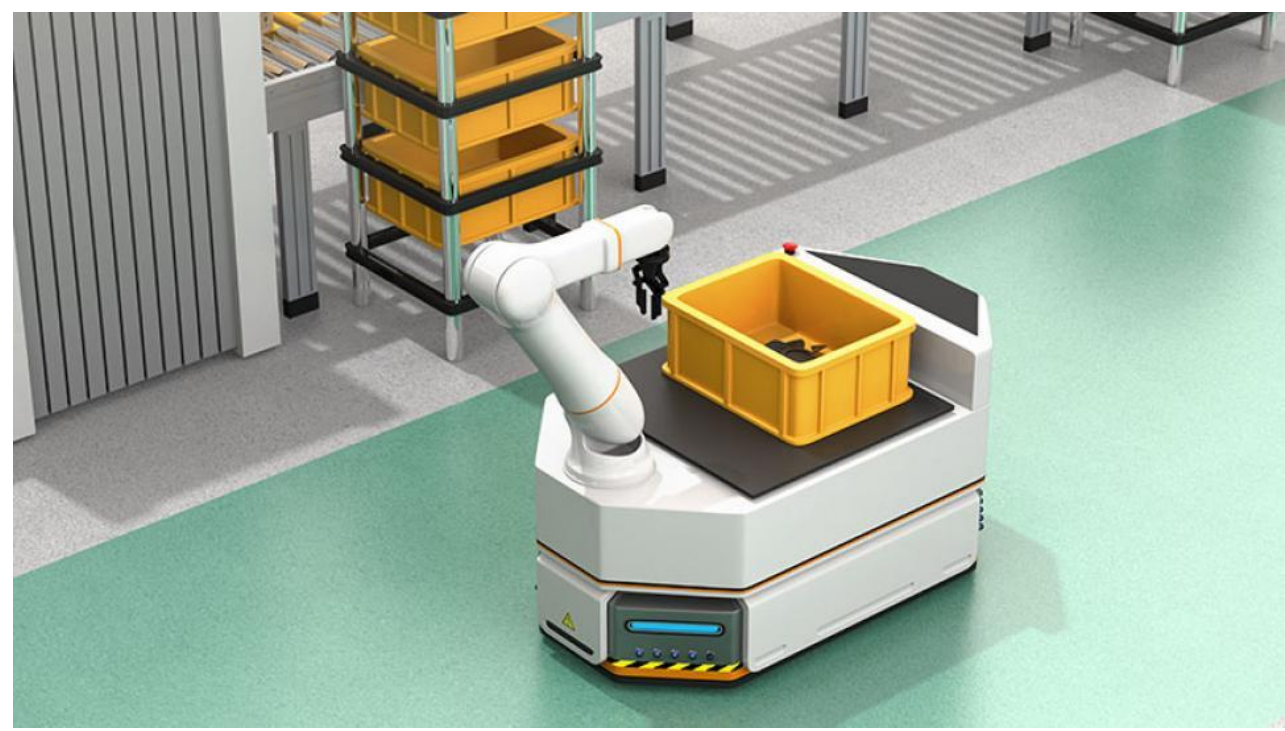

Figure 4. Automated Guided Vehicle - AGV [9] 
Painting and welding robots with $\mathrm{AI}$ are capable of much more than robots of routine tasks. They are capable of detecting defects, finding defective materials and reporting them to quality assurance. [8] [9]

Based on the renowned Lean principles, it is essential that the development of maintenance and production go hand in hand. Numerous literatures on Lean mention the importance of automation, where it is possible, the likelihood of human error should be excluded. [8] [9] [11]

In production, maintenance and operation, we find operators and maintenance personnel at several plants who perform their daily routine tasks. Man-made defects may be costly. Artificial intelligence can be the solution to eliminate these human activities. [8] [9] The AI solutions also have a high prior in other fields. [12] [13] [14]

\section{Summary}

We can see that technology, manufacturing, management and logistics are all connected to each other. We cannot see them separately. Smoother and faster processes is possible with the use of artificial intelligence, but is required to use Industry 4.0 tools, like M2M or M2H. There are many obstacles and the $\mathrm{AI}$ is still under development. But overall it is very beneficial and costs are reduced, time is saved and errors and accidents are prevented. Besides, is expected even more advances in AI in health care, games, advertisement, transportation, navigation and maps, sports, and shopping. On long term the companies can reach a higher efficiency and the vehicles/machines need less maintenance than ever and they can be autonomous. In the not too fa future the artificial intelligence will get a higher prior than ever. The article gives a short description about the importance of Artificial intelligence in vehicle industry.

\section{Acknowledgments}

This research work has been supported by the EFOP-3.6.1-16-2016-00022 project, which is gratefully acknowledged by the authors. The project is co-financed by the European Union and the European Social Fund.

\section{References}

[1] engineerin.com: The Use of $A I$ and VR In Maintenance Management, url: https://www.engineering.com/AdvancedManufacturing/ArticleID/18100/The-Use-of-AI-andVR-In-Maintenance-Management.aspx Downloaded: 2019.08.07. 11:53

[2] ignite: 5 Ways Artificial Intelligence is Impacting the Automotive Industry, url: https://igniteoutsourcing.com/automotive/artificial-intelligence-in-automotive-industry/ Downloaded: 2019.08.07.12:35

[3] Aerospace Manufacturing and Design: Artificial intelligence for predictive maintenance, url: https://www.aerospacemanufacturinganddesign.com/article/artificial-intelligence-forpredictive-maintenance/ Downloaded: 2019.08.06. 13:41 
[4] Gy. Mester: Autonom önvezető robot autók, Dr. Mester Gyula, c. egyetemi tanár, a Magyar Mérnökakadémia rendes tagja, Óbu-dai Egyetem, Biztonságtudományi Doktori Iskola, Budapest url: http://www.vmtt.org.rs/mtn2017/402_417_Mester.pdf Downloaded: 2019.08.06. 13:45

[5] G. Husi: Ipar 4.0, 2016.11.16. Debreceni Egyetem Műszaki Kar, Jegyzet

[6] AD: Here's Why BMW Is Approaching Autonomous Driving in the Best Way Possible, url: https://www.architecturaldigest.com/story/bmw-approaching-autonomous-driving-best-waypossible Downloaded: 2019.08.06. 14:26

[7] Human - Autonomy Sciences: Throwback Thursday: A model for types and levels of automation, url: https://www.humanautonomy.com/blog/2017/11/8/throwback-levels-of-automation Downloaded: 2019.08.06 13:48

[8] WebWire: Hyundai Motor Group Ventures Further Into New Robotics Industry of the Future, url: https://www.webwire.com/ViewPressRel.asp?aId=230397 Downloaded: 2019.08.06. 13:49

[9] Vaisala: Developing Automated Guided Vehicles for Internal Factory Material Movements, url: https://www.vaisala.com/en/blog/2019-03/developing-automated-guided-vehicles-internalfactory-material-movements Downloaded: 2019.08.06. 11:50

[10] Khairy A HKobbacy: Application of Artificial Intelligence in Maintenance Modelling and Management, IFAC Proceedings Volumes, Volume 45, Issue 31, 2012, Pages 54-59, ISSN 14746670

[11] A. Matkó, S. Malhotra: Implementing 5S in a Hungarian Company, International Journal of Engineering and Management Sciences $3: 5$ pp. 161-173. , 13 p. (2018)

[12] Kulcsár, B ; Bohács, G ; Gódor, B ; Hajdu, S: Some remarks on the development of the navigation of mobile robots using a mobile robot for demonstrational purposes pp. 101-106. , 6 p. In: J, Bitó; I, Rudas; J, Tar (szerk.) RAAD 2002 Proceedings of the 11th International Workshop on Robotics in Alpe-Adria-Danube Region Balatonfüred, Magyarország : IEEE, (2002)

[13] Kulcsár, B ; Bohács, G ; Gódor, B ; Hajdu, S: Comparing analyze of solution for mobile robot abstacle avoidance pp. 364-369. , 6 p. In: IEEE (szerk.) Proceedings of the 13th International Workshop on Robotics in Alpe-Adria-Danube Region New York, Amerikai Egyesült Államok: IEEE, (2004)

[14] A., Szántó; S., Hajdu: Vehicle Modelling and Simulation in Simulink. International Journal of Engineering and Management Sciences / Müszaki és Menedzsment Tudományi Közlemények 4 : 1 pp. $260-265 ., 6$ p. (2019) 